\title{
Co Incorporation on Structure, Conductivity and Magnetism of $\mathrm{GaFeO}_{3}$
}

\author{
XIA Zhaoyang ${ }^{1,2}$, WANG Hui ${ }^{1}$, FANG Jinghong ${ }^{1,2}$, ZHANG Yang ${ }^{1}$, WANG Chaoyue ${ }^{1}$, \\ HE Huan ${ }^{1}$, NI Jinqi ${ }^{1}$, SHI Yun ${ }^{1}$, LI Qin ${ }^{1}$, YU Jianding ${ }^{1,2}$ \\ (1. Shanghai Institute of Ceramics, Chinese Academy of Sciences, Shanghai 200050, China; 2. University of Chinese Academy \\ of Sciences, Beijing 100049, China)
}

\begin{abstract}
GaFeO}_{3}$ is one of the most promising ferromagnetic materials due to its magnetoelectric coupling effect. $\mathrm{GaFe}_{1-x} \mathrm{Co}_{x} \mathrm{O}_{3}(x=0,0.02,0.05,0.07,0.10)$ ceramics were prepared by the conventional solid-state method, and the effect of Co substitution on the microstructure, electrical leakage and magnetic properties was investigated. The XRD patterns and Rietveld refinement using the FullProf package showed that the secondary phase with a Fd $\overline{3} \mathrm{~m}$ space group was present in addition to the main GFO phase with a Pc2 ${ }_{1} \mathrm{n}$ space group, and with an increase of Co doping, the proportion of the secondary phase and the lattice distortion increased. The leakage current density of the GFCO- $x$ samples decreased by approximately 7 orders of magnitude for $\mathrm{Co}=2 \mathrm{at} \%$. The improved magnetization in GFCO ceramics was attributed to the secondary phase and enhanced lattice distortion. This work suggests that the magnetism was improved by doping Co and the leakage current would be decreased sharply without prominent fluctuation of $T_{\mathrm{C}}$ in the meantime by the incorporation of trace amounts of Co.
\end{abstract}

Key words: Co-doping $\mathrm{GaFeO}_{3}$; solid-state sintering; leakage; magnetic transition temperature

Multiferroic materials have recently attracted extensive attention due to their attractive physical properties, such as ferromagnetism, ferroelectricity and ferroelasticity. Moreover, these coexisting properties can also result in coupling effects, such as the magnetoelectric (ME) effect, the cross-coupling between the ferromagnetic and ferroelectric properties. Based on the modified requirements: multifunctional, miniaturized and high-performance circuit, the storage devices are seeking for other possibilities except the traditional semiconductor technics ${ }^{[1-3]}$, like magnetoelectric random access memory (MERAMs) worked as electrically written and magnetically read ${ }^{[4]}$ and multiple-state magnetoelectric memory ${ }^{[5]}$.

As a member of multiferroic family, $\mathrm{GaFeO}_{3}(\mathrm{GFO})$ is one of the most promising materials because of its good piezoelectricity at room temperature ${ }^{[6-8]}$, near roomtemperature ferrimagnetism ${ }^{[9-10]}$, and pronounced lowtemperature ME effects ${ }^{[11]}$. Although GFO owns such attractive features, its large electrical leakage and lower magnetic transition temperature limit its application as storage devices. Therefore, its leakage current must be reduced and its magnetic transition temperature $\left(T_{\mathrm{C}}\right)$ and magnetic properties should be improved ${ }^{[12-15]}$.

The conduction mechanism of GFO ceramics is studied through annealing at different atmosphere, and it was found that the leaky behavior of GFO mainly results from the oxygen vacancies and $\mathrm{Fe}$ valance fluctuation $^{[16-18]}$. Several groups ${ }^{[17-22]}$ explored the effects of doping in order to reduce the leakage currents and discovered that the incorporation of some bivalent cation ions can effectively decrease the leakage current by weakening the hopping processes between $\mathrm{Fe}^{2+}$ and $\mathrm{Fe}^{3+}$ states. Han, et $a l^{[23]}$ demonstrated that both magnetization and $T_{\mathrm{C}}$ of GFO nanoparticles are enhanced with the presence of Co contents. Moreover, the reduction of the leakage current is then expected in bivalent Co ions substituted bulk GFO. In this work, we studied the effect of Co incorporation on the structure, conductivity and magnetism of GFO ceramics. The results manifested that the multiferroic properties of GFO were well improved

Received date: 2020-04-07; Revised date: 2020-06-29; Published online: 2020-09-10

Foundation item: Joint Funds of the National Natural Science Foundation of China (U1738114); Shanghai Science and Technology Committee (19DZ1100703, 19511107600); Shanghai Sailing Program (17YF1421500); Collaborative Research Project of Laboratory for Materials and Structures, Institute of Innovative Research, Tokyo Institute of Technology

Biography: XIA Zhaoyang(1995-), female, Master candidate. E-mail: Karenxzy@mail.ustc.edu.cn

夏朝阳(1995-), 女, 硕士研究生. E-mail: Karenxzy@mail.ustc.edu.cn

Corresponding author: YU Jianding, professor. E-mail: yujianding@mail.sic.ac.cn 余建定, 研究员. E-mail: yujianding@mail.sic.ac.cn 
with proper Co substitution. The reasons for the leakage reduction and improved multiferroic properties were discussed based on components and lattice distortion.

\section{Experimental}

A series of $\mathrm{GaFe}_{1-x} \mathrm{Co}_{x} \mathrm{O}_{3}(x=0,0.02,0.05,0.07,0.10)$ ceramics have been fabricated with conventional solidstate sintering technology. The starting powders including gallium oxide $\left[\mathrm{Ga}_{2} \mathrm{O}_{3},(99.99 \%\right.$, aladdin $\left.)\right]$, ferric oxide $\left[\mathrm{Fe}_{2} \mathrm{O}_{3}(99.99 \%\right.$, Rare Metallic Co Ltd)] and cobalt monoxide [CoO (AR, aladdin)] were carefully weighed in stoichiometric ratio and thoroughly balled-milled with absolute ethanol and agate balls for $12 \mathrm{~h}$. After that, the mixed powder was dried and passed through a 100-mesh $(150 \mu \mathrm{m})$ sieve. The dried mixture was precalcined at $900{ }^{\circ} \mathrm{C}$ in air in a muffle furnace for $6 \mathrm{~h}$. After it cooled down, the mixture was ground into powder again and pressed into rods by the cold isostatic press, then the rods were calcined at $1350{ }^{\circ} \mathrm{C}$ in air for $10 \mathrm{~h}$ afterwards. Samples with different cobalt contents, 0, 2at $\%$, 5at $\%$, $7 \mathrm{at} \%$, and $10 \mathrm{at} \%$ were denoted as GFCO-0, GFCO-1, GFCO-2, GFCO-3, and GFCO-4, respectively. The as-prepared samples were sliced into flat pieces or ground into powder for further measurement.

The powder X-ray diffraction patterns (XRD) for the crushed GFCO ceramics were obtained at room temperature using an Ultima-IV $(\lambda=0.15406 \mathrm{~nm})$ with $\mathrm{CuK} \alpha$ radiation $(\lambda=0.15406 \mathrm{~nm})$, and the step scan mode was chosen with $0.01^{\circ}$ per step and $2 \mathrm{~s}$ collection time. Refinement of the lattice constants was achieved with the Fullprof package. The morphology of the GFCO- $x$ ceramics was observed with scanning electron microscopy (SEM, S-3400N TypeI), and the homogeneity of the components was determined with energy-dispersive X-ray spectroscopy (EDX, S-4800). A physical properties measurement system (PPMS-9 $(\mathrm{dxl})$ ) was used to investigate the magnetization of the samples. The M-H loops were carried out at $300 \mathrm{~K}$ with a field of $1.58 \times 10^{5} \mathrm{~A} / \mathrm{m}$, while the magnetization versus temperature curves were obtained with a field of $7.9 \times 10^{4} \mathrm{~A} / \mathrm{m}$ and between 50 and $390 \mathrm{~K}$. For the measurement of the ferroelectric properties, electrodes were prepared on the samples via gold electroplating. $I-V$ curves and $P-E$ loops at room temperature were measured using a Keithley 6517B electrometer and ferroelectric analyzer (TF2000E).

\section{Results and discussion}

The XRD patterns of the GFCO- $x$ ceramics at room temperature are shown in Fig. 1. The XRD spectra confirmed that cobalt was doped in the gallium ferrite without original phases, such as $\mathrm{CoO}, \mathrm{Fe}_{2} \mathrm{O}_{3}, \mathrm{Ga}_{2} \mathrm{O}_{3}$. There were two phases observed, one was $\mathrm{GaFe}_{1-x} \mathrm{Co}_{x} \mathrm{O}_{3}$ possessed an orthorhombic structure with $\mathrm{Pc} 2{ }_{1} \mathrm{n}$ space group, the other was secondary phase with a cubic structure and the $\mathrm{Fd} \overline{3} \mathrm{~m}$ space group. The FullProf package was used to obtain the Rietveld refinement results, which were exhibited in Fig. 2. The refinement results also obtained the ratio of both phases which were listed in Table 1. The refined lattice parameters of the undoped GFO, namely, $a=0.873659 \mathrm{~nm}, b=0.938267 \mathrm{~nm}$, and $c=0.50766 \mathrm{~nm}$, are consistent with those in previous reports $^{[11,24]}$.

Fig. 3 depicted the variation in the cell parameters of GFCO- $x$, and the cell unit volume and lattice parameters decreased with the incorporation of $\mathrm{Co}$, which correlated with the ionic radius of $\mathrm{Co}^{2+}(0.074 \mathrm{~nm})$ and $\mathrm{Co}^{3+}$ $(0.061 \mathrm{~nm})$ being smaller than that of $\mathrm{Fe}^{2+}(0.078 \mathrm{~nm})$ and $\mathrm{Fe}^{3+}(0.064 \mathrm{~nm})$. The orthorhombic distortion values $(c / a$ and $\sqrt{2} c / b)$ were 0.581074 and 0.765176 for GFO, respectively, while the values of $c / a$ and $\sqrt{2} c / b$ for GFCO- $x$ (0.58116 and 0.765325, 0.51221 and 0.765472 , and 0.581314 and 0.765560 , respectively) were larger than those of GFO, which implied an increase in the lattice distortion. The numerical criteria $R_{\mathrm{WP}}$ and $\chi^{2}$ were $15-18$ and 1-2, proving reliability for this refinement.

Fig. 4 illustrates the morphologies of the GFCO- $x$ samples. The particle size ranged from 2-14 $\mu \mathrm{m}$, and their average sizes were $6.7,4.4,5.4$, and $5.1 \mu \mathrm{m}$, respectively. Hence, the proportion of grain boundaries increased due to the incorporation of Co. Abnormally small

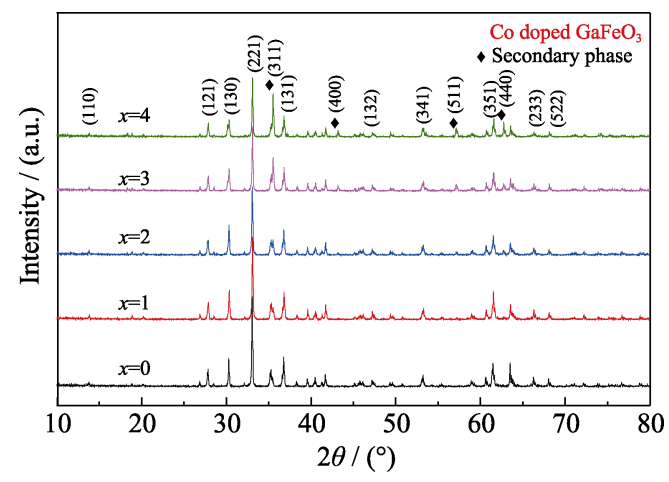

Fig. 1 XRD patterns of GFCO- $x$ ceramics at room temperature

Table 1 Phase ratios for GFCO- $x(x=0,1,2,3,4)$ samples calculated by Rietveld refinement

\begin{tabular}{ccc}
\hline Sample & Main phase & Secondary phase \\
\hline GFCO-0 & $100.00(0.88)$ & - \\
GFCO-1 & $98.37(0.95)$ & $1.63(0.20)$ \\
GFCO-2 & $96.43(0.49)$ & $3.57(0.18)$ \\
GFCO-3 & $77.52(0.94)$ & $22.48(0.50)$ \\
\hline
\end{tabular}



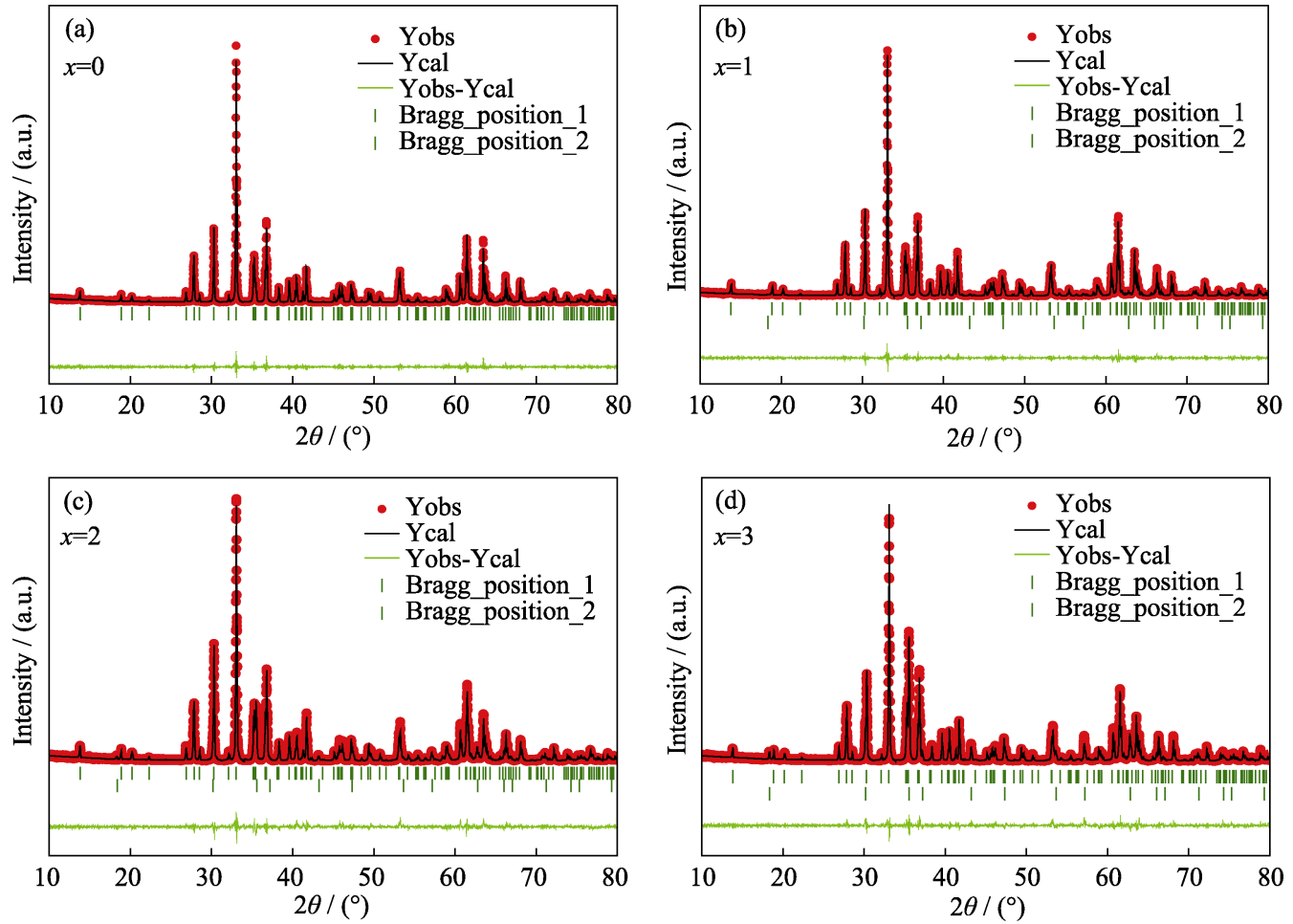

Fig. 2 Rietveld refined XRD patterns of GFCO- $x$ ceramics prepared by conventional solid-state sintering method
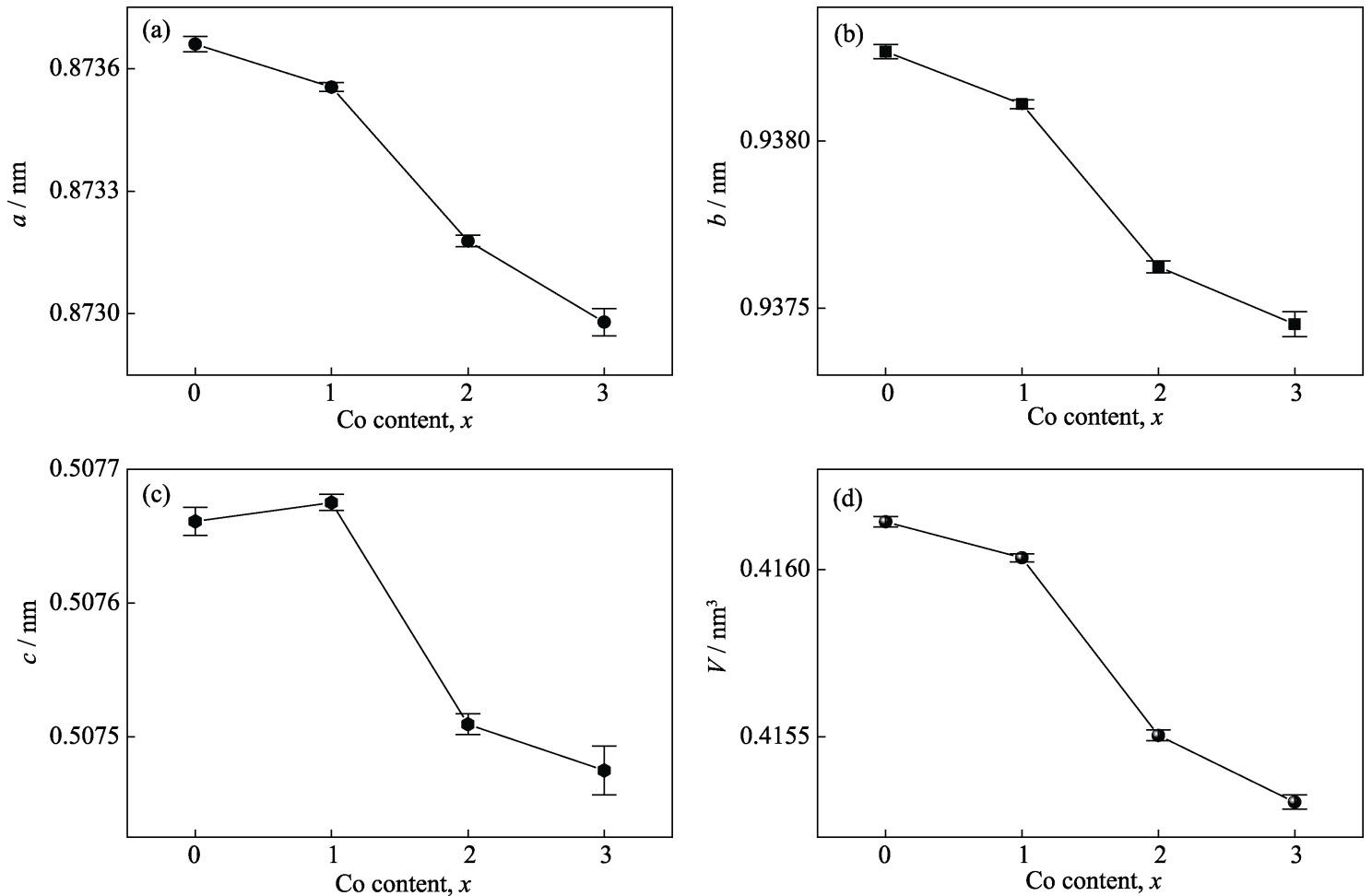

Fig. 3 Composition versus cell unit parameters for (a) $a$, (b) $b$, (c) $c$, (d) $V$

grains denoted as the secondary phase were observed because of the doping of Co. In addition, the EDX results of GFCO-1, as shown in Fig. 4(e), confirmed the existence of secondary phase and suggested that the chemical compositions of the samples comprised $\mathrm{GaFe}_{0.99} \mathrm{Co}_{0.01} \mathrm{O}_{3}$ for the main phase and $\mathrm{Ga}_{0.9} \mathrm{Fe}_{1.4} \mathrm{Co}_{0.7} \mathrm{O}_{4}$ for the secon- dary phase. Moreover, the microstructure of the secondary phase is identical to Ga doped $\mathrm{CoFe}_{2} \mathrm{O}_{4}{ }^{[25]}$.

The curves for the current density versus applied field for the GFCO- $x(x=0,1,2)$ samples measured by a ferroelectric analyzer (TF2000E) are shown in Fig. 5(a). The current density decreased greatly due to the presence 

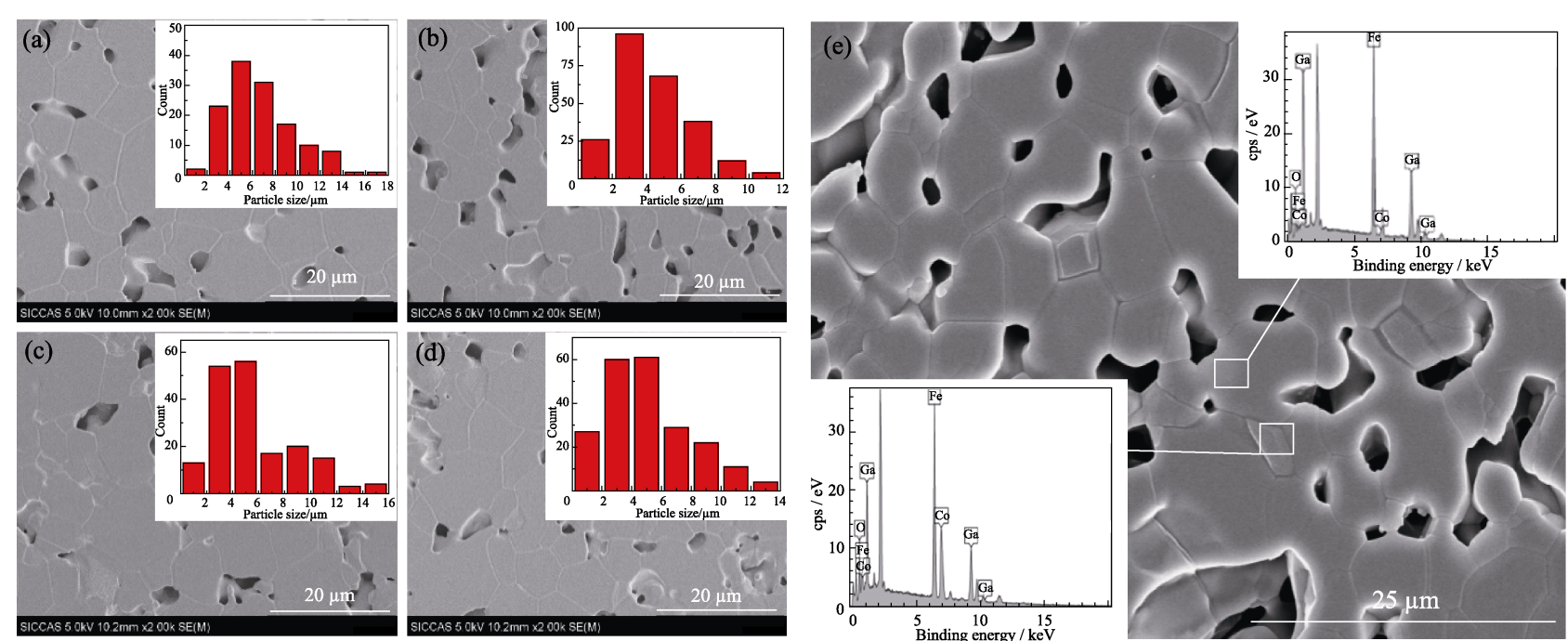

Fig. 4 SEM morphologies of GFCO- $x$ samples and the insets are the distribution of particles size ((a) $x=0$, (b) $x=1$, (c) $x=2$, (d) $x=3$ ); (e) EDS spectra of two phases in GFCO-1 sample
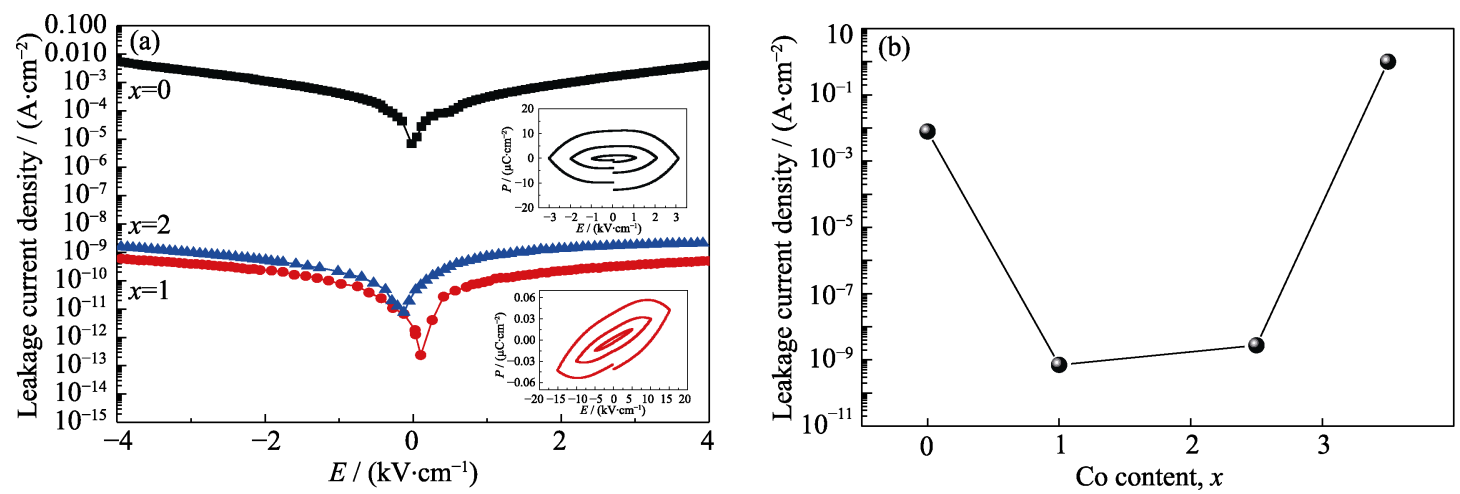

Fig. 5 (a) Current density curves as a function of applied field in the GFCO- $x(x=0,1,2)$ ceramics, with insets showing P-E loops of GFO and GFCO-1; (b) Variation of current density in the GFCO-x ceramics

of Co, especially when doping a slight amount, while the insets of Fig. 5(a) showed that the polarization value decreased drastically. However, the current density increased so rapidly when the Co content reached $7 \%$ that we could not measure the current with the same tester. Instead, the current was measured with a Keithley 6517B electrometer, as shown in Fig. 5(b), while it's obvious that the incorporation of $2 \mathrm{at} \%$ cobalt decreased leakage current density sharply.

The variation in the current density versus Co content as depicted in Fig. 5(b), is similar to that for GFO-doped $\mathrm{Ni}^{[17]}$. The charge conduction decreased sharply and then increased with Co content increasing. This is commonly attributed to the substitution of $\mathrm{Fe}^{2+}$ with other bivalent ions. The possible process can be described using KrögerVink notation as follows.

Oxygen vacancies produced inevitably during the preparation of GFCO ceramics can be written as:

$$
\mathrm{O}_{\mathrm{O}}^{\times} \rightarrow \mathrm{V}_{\mathrm{O}}^{\prime \prime}+\frac{1}{2} \mathrm{O}_{2}+2 \mathrm{e}^{-}
$$

where $\mathrm{O}_{\mathrm{O}}^{\times}$is the loss of lattice oxygen, and $\mathrm{V}_{\mathrm{O}}^{\prime \prime}$ is a vacancy in the oxygen site with double positive charge. The released charge may be captured by $\mathrm{Fe}^{3+}$ ions to satisfy the charge balance, and then $\mathrm{Fe}^{3+}$ is reduced to $\mathrm{Fe}^{2+}$ :

$$
\mathrm{Fe}_{\mathrm{Fe}}^{\times}+\mathrm{e}^{-} \rightarrow \mathrm{Fe}_{\mathrm{Fe}}^{\prime} \text {. }
$$

The coexistence of $\mathrm{Fe}^{3+}$ and $\mathrm{Fe}^{2+}$ allows electrical conduction via the hopping mechanism. However, the substitution of Fe with Co creates holes according to:

$$
\mathrm{CoO} \rightarrow \mathrm{Co}_{\mathrm{Fe}}^{\prime}+h^{\cdot}+\frac{1}{2} \mathrm{O}_{2}
$$

Where $\mathrm{Co}_{\mathrm{Fe}}^{\prime}$ indicates that $\mathrm{Co}$ is in the $\mathrm{Fe}$ site and has an extra negative charge, and $h^{\bullet}$ stands for a hole. These holes are recombined with electrons as follows:

$$
h^{\bullet}+\mathrm{e}^{-} \rightarrow 0
$$

It is believed that the charge carriers are responsible for the leakage current of GFCO, and the recombination of holes and electrons weakens this electrical conduction.

Another reason for the decreased electrical conduction 
is the incorporation of elements that cause a large lattice distortion and increase the scattering of the conduction electrons. As mentioned earlier, the values of $c / a$ and $\sqrt{2} c / b$ for the GFCO- $x$ samples are larger than those for the GFO, which indicates a larger lattice distortion. Fig. 5(b) shows that the leakage current density decreased by almost seven orders of magnitude; nonetheless, referring to published reports, the incorporation of elements reduced the leakage current density by up to four orders of magnitude at most ${ }^{[17,19-20]}$. Thus, there are probably other reasons to explain the decrease in the electrical conduction, such as the introduction of a secondary phase. SEM analysis of the GFCO- $x$ microstructures depicted the presence of a very small secondary phase that was distributed uniformly in the samples, which increased the proportion of crystal boundaries and hindered the electron scattering between the grains, thus, electrical conduction further decreased. However, when the contents of substituted $\mathrm{Co}$ are too high compared to the number of oxygen vacancies, Co plays as a p-type acceptor, and the material becomes a p-type conductor. Moreover, the proportion and size of secondary phase increased correspondingly, so the leakage current of $7 \%$ Co-doped samples increased.

Fig. 6(a) shows the $M(T)$ curves for the GFCO- $x$ ( $x=0$, $1,2,3,4)$ samples, which were measured in zero-fieldcooled (ZFC) mode. The hysteresis loops of all GFCO samples at room temperature with an applied field of 20000 Oe were displayed in Fig. 6(b). Fig. 6 indicated that the Co doping GFO ceramics owned enhanced magnetism which is in accordance with previous results ${ }^{[21-22,26-27]}$. The magnetism of $\mathrm{GaFeO}_{3}$ can be explained by the presence of unequal and antiparallel $\mathrm{Fe}$ moments and $\mathrm{Co}$ moments in $\mathrm{Fe} 1$ and $\mathrm{Fe} 2$ sites along the $c$ axis ${ }^{[11,28]}$. With the substituted $\mathrm{Co}$ on $\mathrm{Fe}$-site whose magnetic moment isn't equal to Fe's, the net magnetic moment increased along the $c$ axis. GFCO ceramics still possessed magnetism after the main phase transformed into a paramagnet at elevated temperatures. Hence, it suggested that there was two $T_{\mathrm{C}}$ in GFCO ceramics, one is near $200 \mathrm{~K}$ and the other is higher than $400 \mathrm{~K}$, and that the secondary phase is responsible for the higher $T_{\mathrm{C}}$. According to published papers ${ }^{[25]}, \mathrm{CoGa}_{x} \mathrm{Fe}_{2-x} \mathrm{O}_{4}$ ( $x=$ $0-0.8$ ) possessed varied $T_{\mathrm{C}}$ from 773 to $523 \mathrm{~K}$. While both $\mathrm{CoGa}_{x} \mathrm{Fe}_{2-x} \mathrm{O}_{4}$ and the secondary $\mathrm{Ga}_{0.9} \mathrm{Fe}_{1.4} \mathrm{Co}_{0.7} \mathrm{O}_{4}$ phase had cubic microstructures with a $\mathrm{Fd} \overline{3} \mathrm{~m}$ space group and similar elemental proportions. Thus, we inferred that the as-prepared GFCO- $x$ ceramics had two magnetic transition temperatures, and the higher $T_{\mathrm{C}}$ was attributed to the secondary phase.

\section{Conclusions}

In conclusion, $\mathrm{GaFe}_{1-x} \mathrm{Co}_{x} \mathrm{O}_{3}(x=0,0.02,0.05,0.07$, $0.10)$ ceramics were prepared by the conventional solid-state method. X-ray characterization and Rietveld refinement results revealed that the as-prepared GFCO- $x$ samples possessed an orthorhombic crystal structure with a $\mathrm{Pc}_{1} \mathrm{n}$ space group for the GFO and a cubic crystal structure with a $\mathrm{Fd} \overline{3} \mathrm{~m}$ space group for the secondary phase. Moreover, the more Co content was doped, the higher proportion of the secondary phase there was, so did the degree of crystal distortion. The surface morphology of the GFCO samples was analyzed using SEM, which indicated that the mean grain size diminished and the proportion of grain boundary increased because of the presence of Co. The Co content doping and secondary phase decreased the leakage current effectively, especially the leakage current of the $2 \mathrm{at} \%$ Co-doped GFO ceramics decreased by approximately 7 orders of magnitude compared to that of the undoped GFO ceramics. Moreover, doping Co improved the magnetic property because of the secondary phase and enhanced lattice distortion. This work shows that Co has a positive influence on magnetism and trace amounts of Co incorporation in $\mathrm{GaFeO}_{3}$ can decrease leakage current sharply, while excess Co leads to the drastic rebound in leakage current.
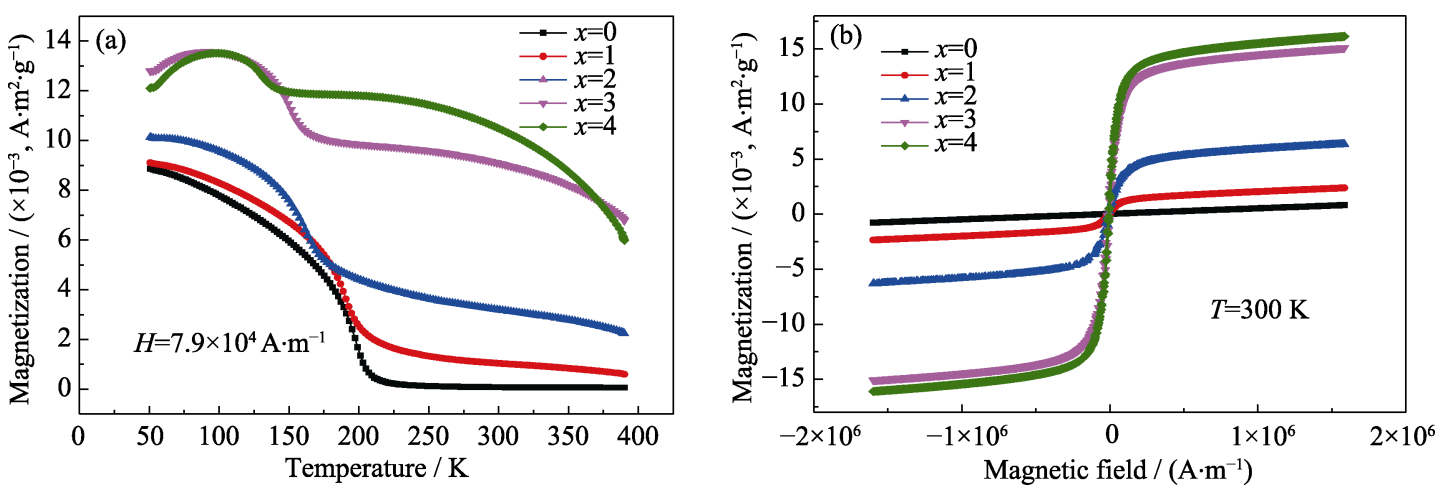

Fig. 6 (a) Temperature dependence of the magnetization for GFCO- $x$ samples and (b) $M-H$ curves of GFCO- $x$ samples at $300 \mathrm{~K}$ 


\section{References:}

[1] EERENSTEIN W, MATHUR N D, SCOTT J F. Multiferroic and magnetoelectric materials. Nature, 2006, 442(7104): 759-765.

[2] FIEBIG M, LOTTERMOSER T, MEIER D, et al. The evolution of multiferroics. Nature Reviews Materials, 2016, 1(8): 16046.

[3] WEI Y X, JIN C Q, ZENG Y M. Progress of relaxor multiferroic materials. Journal of Inorganic Materials, 2017, 32(10): 1009-1017.

[4] SCOTT J F. Multiferroic memories. Nature Materials, 2007, 6(4): 256-257.

[5] BIBES M, BARTHÉLÉMY A. Towards a magnetoelectric memory. Nature Materials, 2008, 7(6): 425-426.

[6] ROY A, MUKHERJEE S, GUPTA R, et al. Structure and properties of magnetoelectric gallium ferrite: a brief review. Ferroelectrics, 2014, 473(1): 154-170.

[7] YAN H, HUANG Y, CUI W, et al. Magnetic properties and crystal structure of $\mathrm{Ga}_{2-x} \mathrm{Fe}_{x} \mathrm{O}_{3}$. Powder Diffraction, 2018, 33(3): 195-201.

[8] ABRAHAMS S C, REDDY J M, BERNSTEIN J L. Crystal structure of piezoelectric ferromagnetic gallium iron oxide. The Journal of Chemical Physics, 1965, 42(11): 3957-3968.

[9] MUKHERJEE S, RANJAN V, GUPTA R, et al. Compositional dependence of structural parameters, polyhedral distortion and magnetic properties of gallium ferrite. Solid State Communications, 2012, 152(13): 1181-1185.

[10] TRONC E, CHANÉAC C, JOLIVET J P. Structural and magnetic characterization of $\varepsilon-\mathrm{Fe}_{2} \mathrm{O}_{3}$. Journal of Solid State Chemistry, 1998, 139(1): 93-104.

[11] ARIMA T, HIGASHIYAMA D, KANEKO Y, et al. Structural and magnetoelectric properties of $\mathrm{Ga}_{2-x} \mathrm{Fe}_{x} \mathrm{O}_{3}$ single crystals grown by a floating-zone method. Physical Review B, 2004, 70(6): 064426.

[12] HAN T C, CHEN T Y, LEE Y C. Grain size effect on site-disorder and magnetic properties of multiferroic $\mathrm{GaFeO}_{3}$ nanoparticles. Applied Physics Letters, 2013, 103(23): 232405.

[13] POPOV Y F, KADOMTSEVA A M, VOROB'EV G P, et al. Magnetoelectric effect and toroidal ordering in $\mathrm{Ga}_{2-x} \mathrm{Fe}_{x} \mathrm{O}_{3}$. Journal of Experimental and Theoretical Physics, 1998, 87(1): 146-151.

[14] MOHAMED M B, SENYSHYN A, EHRENBERG $\mathrm{H}$, et al. Structural, magnetic, dielectric properties of multiferroic $\mathrm{GaFeO}_{3}$ prepared by solid state reaction and Sol-Gel methods. Journal of Alloys and Compounds, 2010, 492(1/2): L20-L27.

[15] SZYMAŃSKI K, DOBRZYŃSKI L, BAKR M, et al. Fe cation occupancies in $\mathrm{GaFeO}_{3}$ prepared by Sol-Gel and solid-state reaction. Phase Transitions, 2010, 83(10/11): 824-835.

[16] MUKHOPADHYAY K, MAHAPATRA A S, CHAKRABARTI P K. Enhanced magneto-electric property of $\mathrm{GaFeO}_{3}$ in $\mathrm{Ga}_{1-x} \mathrm{Zn}_{x} \mathrm{FeO}_{3}$ ( $x=0,0.05,0.10)$. Physica B: Condensed Matter, 2014, 448: 214-218.

[17] GHANI A, YANG S, RAJPUT S S, et al. Electric modulation of conduction in multiferroic Ni-doped $\mathrm{GaFeO}_{3}$ ceramics. Journal of Physics D: Applied Physics, 2018, 51(22): 225002.

[18] LEFEVRE C, SHIN R H, LEE J H, et al. Reduced leakage currents and possible charge carriers tuning in $\mathrm{Mg}$-doped $\mathrm{Ga}_{0.6} \mathrm{Fe}_{1.4} \mathrm{O}_{3}$ thin films. Applied Physics Letters, 2012, 100(26): 262904.

[19] SHARMA N, KUMAR S, MALL A K, et al. Effect of Zn Doping on Structural and Ferroelectric Properties of $\mathrm{GaFeO}_{3}$ for Futuristic Spintronic Applications. 2018 IEEE 13th Nanotechnology Materials and Devices Conference (NMDC), IEEE, 2018: 1-4.

[20] THOMASSON A, CHERIFI S, LEFEVRE C, et al. Room temperature multiferroicity in $\mathrm{Ga}_{0.6} \mathrm{Fe}_{1.4} \mathrm{O}_{3}: \mathrm{Mg}$ thin films. Journal of Applied Physics, 2013, 113(21): 214101.

[21] OH S H, SHIN R H, LEFÈVRE C, et al. Incorporation of cobalt ions into magnetoelectric gallium ferrite epitaxial films: tuning of conductivity and magnetization. RSC Advances, 2015, 5(43): 34265-34271.

[22] KUMAR RAJEEV, MALL KUMAR ASHISH, GUPTA RAJEEV, et al. Raman Effect, Structural and Dielectric Properties of Sol-Gel Synthesized Polycrystalline $\mathrm{GaFe}_{1-x} \mathrm{Zr}_{x} \mathrm{O}_{3} \quad(0 \leqslant x \leqslant 0.15)$. AIP Conference Proceedings, 2016, 1725: 1 .

[23] HAN T C, LEE Y C, CHU Y T. Effect of cobalt doping on site-disorder and magnetic behavior of magnetoelectric $\mathrm{GaFeO}_{3}$ nanoparticles. Applied Physics Letters, 2014, 105(21): 212407.

[24] SONG C, YAN X, LIU Q, et al. Magnetic and ferroelectric properties of indium-doped gallium ferrite. Journal of Magnetism and Magnetic Materials, 2019, 469: 8-12.

[25] SONG S H, LO C C H, LEE S J, et al. Magnetic and magnetoelastic properties of Ga-substituted cobalt ferrite. Journal of Applied Physics, 2007, 101(9): 09C517

[26] WANG Q X. Effect of Co, Zn and Al Doping on the Structural and Properties for Multiferroic $\mathrm{GaFeO}_{3}$. Beijing: China University of Mining and Technology, Master's Dissertation, 2014.

[27] LIU C Z. The Study of the Modification and Multiferroic Properties of $\mathrm{GaFeO}_{3}$ Nano-material. Shanghai: East China Normal University, Master's Dissertation, 2012.

[28] ABRAHAMS S C, REDDY J M. Magnetic, electric, and crystallographic properties of gallium iron oxide. Physical Review Letters, 1964, 13(23): 688.

\title{
$\mathrm{Co}$ 掺杂 $\mathrm{GaFeO}_{3}$ 陶瓷的结构、导电及磁性能研究
}

\author{
夏朝阳 ${ }^{1,2}$, 王 慧 ${ }^{1}$, 方婧红 ${ }^{1,2}$, 张 阳 $^{1}$, 汪超越 ${ }^{1}$, \\ 贺 欢 ${ }^{1}$, 倪津崎 ${ }^{1}$, 石 云 $^{1}$, 李 勤 $^{1}$, 余建定 ${ }^{1,2}$ \\ (1. 中国科学院 上海硅酸盐研究所, 上海 200050; 2. 中国科学院大学, 北京 100049)
}

\begin{abstract}
摘 要: $\mathrm{GaFeO}_{3}$ 因其磁电耦合效应成为目前极具潜质的多铁性材料之一。本工作采用固相烧结法制备了不同钻掺杂 浓度的铁酸镓陶瓷, 并研究了钴的掺杂浓度对铁酸镓陶瓷的相组成, 微观结构形貌, 漏电流及磁性的影响。XRD 及 Rietveld 精修结果显示除了主相 $\mathrm{GaFeO}_{3}$, 还存在第二相, 且随着钴含量的增加, 第二相含量逐渐增加, 晶体的畸变 程度增大; 因为掺入二价阳离子 $\mathrm{Co}^{2+}$ 并引入了第二相, 样品的漏电性能和纯 $\mathrm{GaFeO}_{3}$ 陶瓷相比显著改善; 当钴掺杂 浓度为 $2 \mathrm{a} t \%$ 时, 样品的漏电流密度相较于 $\mathrm{GaFeO}_{3}$ 降低了 7 个数量级; 掺入 $\mathrm{Co}^{2+}$ 引入第二相且晶格畸变程度增加使 得 $\mathrm{GaFeO}_{3}$ 的磁性增强。研究结果表明: 铁酸镓中掺杂微量的钴可以改善磁性, 并使漏电流大幅降低而磁转变温度 无明显下降。
\end{abstract}

关 键 词: 钴掺杂铁酸镓; 固相烧结; 漏电流; 磁转变温度

中图分类号: TQ174 文献标识码: A 